\title{
Comparison of Calcium Hydroxide, Chlorhexidine and Triple Antibiotic Paste As Intracanal Medicaments In Patients With Acute Periapical Infections
}

\author{
Syed Adeel Ahmed, Shama Asghar, Safia Anwar \\ - - - - - - - - - - - - - - - - - - - - - - - - - - - - - -
}

ABSTRACT

Objective: To compare the effects of calcium hydroxide, triple antibiotic paste (TAP) and chlorhexidine (CHX) as the intra-canal medicaments in post-operative pain reduction.

Study Design and Setting: This was a Quasi experimental study conducted in Bahria University Medical and Dental College, Department of Operative Dentistry for the period of six months.

Methodology: Patients with acute periapical infections in single rooted teeth were divided into 3 groups. Group 1 received Calcium hydroxide, group 2 received Chlorhexidine and group 3 received Triple antibiotic paste as intracanal medicament. Each group comprised of 30 patients therefore the total participants of the study were 90 . Patients were recalled on $2 \mathrm{nd}$, 7 th and $15^{\text {th }}$ day postoperatively and the pain was recorded by using Visual Analogue Scale.

Results: Among the study participants; two patients receiving calcium hydroxide were pain free after 2 days and this number increased to 11 patients after 7 days. From the CHX group; nine patients were pain free after two days and 23 patients reported no pain after 7 days. In TAP paste group 3 patients reported no pain after 2 days and 22 after 7 days. No patient reported pain after 15 days in any group. Data was statistically analyzed by using SPSS version 23 and Chi-square test was used for descriptive analysis.

Conclusion: Intra-canal medicaments significantly reduced inter-appointment pain. The chlorhexidine and triple antibiotic paste were more effective as compared to calcium hydroxide.

KEY WORDS: Intra-canal Medicaments, Periapical Infection, Post-operative Pain

\section{INTRODUCTION:}

The reason behind the process of root canal treatment is to remove the infected pulp and eliminate the pain. This is achieved by chemo-mechanical debridement and cleaning of the root canal system followed by filling of the canals known as obturation. Microorganisms have a critical role in the pathogenesis of periapical and periodontal disease; hence their complete elimination is the key for success of root canal procedure. ${ }^{1}$ The long-term success of an endodontic treatment can be affected by immediate post-operative pain in a tooth. The incidence of its occurrence is significantly more in teeth with necrotic pulps due to a larger amount of microorganisms present. ${ }^{2}$ Total elimination of these microorganisms is, however, difficult to accomplish by chemo-mechanical preparation alone. ${ }^{3}$ Placing intra-canal medicaments between appointments helps in the eradication of these microorganisms and promotes successful outcome of endodontic treatment. ${ }^{4}$

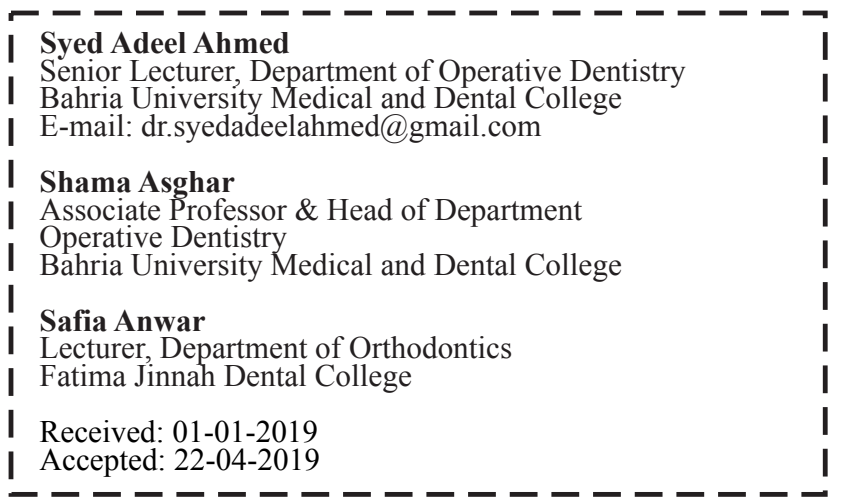

Intra-canal medicaments have been in use since the early 1900 s to augment the chemo-mechanical debridement of the root canal system. ${ }^{5}$ Calcium hydroxide has been in use since 1920 as an intracanal medicament in root canal treatment. Its antibacterial action is attributed to its ability to release hydroxyl ions (OH-). ${ }^{6}$ However, it is not effective against $\mathrm{E}$. faecalis which resides in the deeper parts of dentinal tubules where the $\mathrm{pH}$ tends to be stable because of the buffering action of dentin. ${ }^{7}$ The search for a better alternative has led to the discovery of better antimicrobial agents like Chlorhexidine, metronidazole and a mixture of antibiotics known as triple antibiotic paste.

Chlorhexidine (CHX) has gained wide use in endodontics as an irrigant and intra-canal medicament owing to its superior anti-microbial activity. ${ }^{8}$ The increased efficacy of CHX is attributed to its positively charged molecule which adheres to the negatively charged microbial cell wall, increasing the permeability of the cell wall resulting in cell death. ${ }^{9}$ It is superior to iodine, potassium iodide and calcium hydroxide in removing actinomyces israelii from infected dentinal tubules. ${ }^{10}$

Recently a mixture of ciprofloxacin, metronidazole and minocycline, known collectively as triple antibiotic paste, has been used to disinfect the root canal system. ${ }^{11,12,13,14}$ Triple antibiotic paste when used as an intracanal medicament aids in the development of dentin-pulp complex in immature teeth with pulp necrosis. ${ }^{15}$ The rationale of the study was to find out the most effective intra-canal medicament for such cases in endodontics. 
The purpose of this study was to evaluate the effects of calcium hydroxide, chlorhexidine and triple antibiotic paste as intra-canal medicaments on the inter-appointment pain in patients undergoing endodontic treatment with acute periapical infection.

\section{MATERIALS AND METHODS:}

This study was a quasi-experimental study design, conducted in the Department of Operative Dentistry, Bahria University Dental Hospital Karachi for a period of six months (April 2018 - September 2018). Total 90 patients with acute periapical infection in single rooted teeth were randomly divided into three groups of 30 each. Informed and written consent was obtained from all the participants. Patients between ages 17-55 and had acute pariapical infection in single rooted teeth with closed apices were included in the study. Immune-compromised patients with open apex, vertical or horizontal root fractures were excluded from the study. The patients in the first group (30) were given calcium hydroxide as intracanal medicament. The second group (30) received chlorhexidine, while the third group was given triple anti-biotic paste as intra-canal medicament. The root canals were performed by a single operator with significant experience in endodontics. In each group, pulpectomy was done using Hedstorm file no. 20 and the canals were prepared manually using a crown down technique. After preparation, canals were dried using paper points and intra-canal medicaments were placed using a lentulo spiral. Patients were recalled after $2 \mathrm{nd}, 7$ th and 15 th day post operatively and pain was recorded using the visual analogue scale $e^{16}$ on the following criteria: No pain $=0$; mild pain but no medication required $=1-3$; moderate pain that required a mild analgesic $=4$ 7 ; severe pain not responding to mild analgesic $=8-10$. Patients who reported pain were prescribed flurbiprofen (Tablet Froben ${ }^{\circledR} 100 \mathrm{mg}$ ). The scores were recorded by one observer. The statistical analysis was done on SPSS version 23 and chi-square test was used to compare the results at a significance level of $\mathrm{P}-$ value $<0.05$.

\section{RESULTS:}

A total of 90 patients participated in the study; aged between 17 and 54 with a mean age of 32.33 males and 57 females. In the calcium hydroxide group (Group 1) after 2 days, 9 patients showed VAS scores of 1-3 and 21 patients had scores of 4-7. No patients reported score 0 . After 7 days, 11 patients reported no pain while 19 patients had scores 1-3. None of the patients complained of pain after 15 days. In the chlorhexidine group (Group 2), 9 patients reported score 0 and 21 had scores of 1-3 after 2 days. After 7 days, 23 patients had score 0 while 7 patients reported scores 1-3. None of the patients reported pain after 15 days. In group 3 (Triple antibiotic paste), 3 patients reported score 0 after 2 days while 27 patients had scores of 1-3. After 7 days, 22 patients reported no pain and 8 patients had scores of 1-3. None of the patients described pain after 15 days. Chi-square test was used to compare VAS scores of three intracanal medicaments, results depicted better effects for chlorhexidine and triple antibiotic paste than calcium hydroxide in controlling inter-appointment pain after 02 days ( $\mathrm{p}$-value $=0.000$ ) and 07 days ( $p$-value $=0.002$ ). (Table 1$)$ A comparison between gender and VAS scores of intracanal medicaments also revealed significant relationship after 2 days ( $\mathrm{p}$-value= 0.007), 7 male patients reported no pain and 24 reported scores of 1-3, while 33 female patients observed the scores of 1-3 and 19 reported the scores of 4-7. After 7 days, 31 male patients reported score 0 while 25 female patients reported score 0 and 32 reported scores of $1-3$ with $p$-value $=$ 0.000. (Table-2)

DISCUSSION: The success of endodontic treatment in teeth with pulpal necrosis or periapical lesions is based upon the effective removal of detrimental microorganisms from the root canal system. In addition to chemo-mechanical debridement, intra-canal medicaments have been proven to be valuable aides in root canal disinfection. ${ }^{17}$ The results of our study reinforced this concept, as the pain caused by these remnant microorganisms was significantly decreased

Table-1: Comparison Of Intra-Canal Medicaments And Vas Scores On Day 2, 7, 15

\begin{tabular}{|c|c|c|c|c|c|}
\hline Intracanal Medicament & $\begin{array}{c}\text { VAS score } \\
0\end{array}$ & \begin{tabular}{|c} 
VAS score \\
$\mathbf{1 - 3}$
\end{tabular} & $\begin{array}{c}\text { VAS score } \\
4-7 \\
\end{array}$ & \begin{tabular}{|c} 
VAS score \\
$8-10$
\end{tabular} & P-Value \\
\hline \multicolumn{5}{|c|}{ 型 } & \multirow{4}{*}{0.000} \\
\hline Calcium Hydroxide & 0 & 9 & 21 & 0 & \\
\hline Chlorhexidine & 9 & 21 & 0 & 0 & \\
\hline Triple Antibiotic Paste & 3 & 27 & 0 & 0 & \\
\hline \multicolumn{5}{|l|}{ Day 7} & \multirow{4}{*}{0.002} \\
\hline Calcium Hydroxide & 11 & 19 & 0 & 0 & \\
\hline Chlorhexidine & 23 & 7 & 0 & 0 & \\
\hline Triple Antibiotic Paste & 22 & 8 & 0 & 0 & \\
\hline \multicolumn{5}{|l|}{ Day 15} & \multirow{4}{*}{----} \\
\hline Calcium Hydroxide & 0 & 0 & 0 & 0 & \\
\hline Chlorhexidine & 0 & 0 & 0 & 0 & \\
\hline Triple Antibiotic Paste & 0 & 0 & 0 & 0 & \\
\hline
\end{tabular}


Table -2: Comparison Between Gender And Vas Scores Of Three Intercanal Medicaments

\begin{tabular}{|l|c|c|c|c|c|}
\hline Gender & VAS 0 & VAS 1-3 & VAS 4-7 & VAS 8-10 & P-value \\
\hline Day 2 \\
\hline $\begin{array}{c}\text { Male } \\
\text { Female }\end{array}$ & 5 & 24 & 2 & 0 & 0.007 \\
\hline Day 7 & 33 & 19 & 0 & \\
\hline Male & 31 & 2 & 0 & 0 & 0.000 \\
Female & 25 & 32 & 0 & 0 & \\
\hline Day 15 & \multicolumn{7}{|l}{} \\
\hline Male & 33 & 0 & 0 & 0 & ----- \\
Female & 57 & 0 & 0 & 0 & \\
\hline
\end{tabular}

in patients who earlier reported pain.

The results of our study showed that chlorhexidine and triple antibiotic paste were more effective in reducing interappointment pain than calcium hydroxide on days 2 and 7. The efficacy of all three medicaments was recorded equal on day 15 . This result is in accordance with most studies comparing the three as intra-canal medicaments. ${ }^{18,19}$ The anti-microbial activity of calcium hydroxide is due to its alkalinizing action in which ionization turns into hydroxyl ions. The hydroxyl ions deactivate bacterial lipopolysaccharides of gram negative bacteria, which are predominantly involved in root canal infections and the associated pain. ${ }^{20}$ The present study shows effective pain relief from calcium hydroxide, with profound improvement in first 7 days and this was in harmony with the studies of Gome et $\mathrm{al}^{21}$ de Souza-Filho et $\mathrm{al}^{22}$ and Gomes et $\mathrm{al}^{23}$.

The antibacterial effect of chlorhexidine is attributed due to its ability to adsorbed in the anionic substrate and be subsequently released from these site over time (substantivity), thus providing long term antibacterial effect. The results of our study were in agreement with Barbosa et al, who found that the antibacterial effect of chlorhexidine was better than calcium hydroxide. ${ }^{24}$ The present study showed that the efficacy of chlorhexidine in reducing the bacterial endotoxins and thus reducing interappointment pain was better than calcium hydroxide. Signoretti et al also confirms this finding in his in vitro study. ${ }^{25}$ Studies have found that E. faecalis is resistant to calcium hydroxide, especially when a high $\mathrm{pH}$ is not maintained. ${ }^{26}$ Dametto et al in his study showed that $2 \%$ chlorhexidine significantly reduced $E$. faecalis colonies. ${ }^{27}$

Triple antibiotic paste showed higher antibacterial activity than chlorhexidine. ${ }^{28}$ This is in contrast with our study which shows that there was no significant difference between the activities of triple antibiotic paste and chlorhexidine, which was indicated by the fact that the number of patients with reduced pain was almost equal in both these groups. The effect of triple antibiotic paste however, was better than calcium hydroxide, which coincides with the study of Adl A et al. ${ }^{29}$
In regards to the limitations of the study, randomization of the patients was not done before placing them in one of the three groups. The sample size was also limited and a bigger sample size would have added the significance results. The long term follow-up following the treatment would be recommended in future studies.

\section{CONCLUSION:}

The addition of intra-canal medicaments significantly reduces the effects of microbial endotoxins and consequently interappointment pain. In patients with acute periapical infections, triple antibiotic paste and chlorhexidine were found to be significantly better in relieving inter-appointment pain as compared to calcium hydroxide.

\section{REFERENCES:}

1. Lakhani A.A, Sekhar K.S, Gupta .P, Efficacy of Triple Antibiotic Paste, Moxifloxacin, Calcium Hydroxide And 2\% Chlorhexidine Gel In Elimination of E. Faecalis: An In vitro Study, J Clin Diag Res 2017;11(1):6-9

2. Ghoddusi J, Javidi M, Zarrabi MH, Bagheri H. Flare-ups incidence and severity after using calcium hydroxide as intracanal dressing. N Y State Dent J. 2006;72(4):24-8.

3. Khattak YK, Shah SA, Alam F. Comparison of inter appointment pain between calcium hydroxide mixed with $2 \%$ chlorhexidine and calcium hydroxide mixed with normal saline; a randomized controlled trial. JKhyb Col Dent 2014; 5(1): $33-37$

4. Chong B, Ford TP. The role of intracanal medication in root canal treatment. Int Endod J. 1992;25(2):97-106.

5. Mohammadi Z. Antibiotics as Intracanal Medicaments: A Review..J Calif Dent Assoc. 2009;37(2):98-108

6. Moller AJR, Lars F, Gunnar D. Apical peri $\neg$ odontitis development and bacterial response to end $\neg$ odontic treatment. Experimental root canal infections in monkeys with selected bacterial strains. Euro J Oral Sci 2004;112(3):207-15

7. George S, Kishen A, Song P. The role of environmental changes on monospecies biofilm formation on root canal wall by Enterococcus faecalis. J Endod. 2005;31(12):867-72

8. Ferraz C, Dealmeidagomes B, Zaia A, Teixeira F, Desouzafilho F. In vitro assessment of the antimicrobial action and the mechanical ability of chlorhexidine gel as an endodontic irrigant. J Endod. 2001;27(7):452-55

9. Mohammadi Z, Abbott P. The properties and applications of chlorhexidine in endodontics. Int Endod J. 2009;42(4):288302

10. Fuss Z, Rafaeloff R, TaggerM , Szajkis S. Intracanal ph changes of calcium hydroxide pastes exposed to carbondioxide in vitro. JEndod 1996;22:362-364

11. Nosrat A, Seifi A, Asgary S. Regenerative endodontic treatment (revascularization) for necrotic immature permanent molars: a review and report of two cases with a new biomaterial. J Endod. 2011;37(4):562-7

12. Thibodeau B, Teixeira F, Yamauchi M, Caplan DJ, Trope M. Pulp revascularization of immature dog teeth with apical periodontitis. J Endod. 2007;33(6):680-9

13. Petrino JA, Boda KK, Shambarger S, Bowles WR, McClanahan SB. Challenges in regenerative endodontics: a case series. J Endod. 2010;36(3):536-41 
14. Jung IY, Lee SJ, Hargreaves KM. Biologically based treatment of immature permanent teeth with pulpal necrosis: a case series. J Endod. 2008;34(7):876-87

15. Bose R, Nummikoski P, Hargreaves K. A retrospective evaluate on of radiographic outcomes in immature teeth with necrotic root canal systems treated with regenerative endodontic procedures. J Endod. 2009;35(10):1343-9

16. Dall A.Q, Jouhar R, Khoso N.A. Comparison of interappointment pain between ledermix and nointracanal medicament in acute apical periodontitis. JLUMHS. 2011;10(3):106-11

17. Mohammadi Z, Abbot PV. The properties and application of chlorhexidine in endodontics IntEndodJ.2009;42:288-302

18. Almyroudi A, Mackenzie D, McHugh S, Saunders WP. The effectiveness of various disinfectants used asendodontic intra canal medications: an in vitro study.J Endod 2002;28:163-7

19. Krithikadatta J, Indira R, Dorothykalyani AL. Disinfection of dentinal tubuleswith 25 chlorhexidine, 25 metronidazole, bioactive glasswhen compared with calcium hydroxide as intracanal medicaments. JEndod. 2007;33:1473-6

20. Siqueira JF, Lopes HP. Mechanisms of antimicrobial activity of calcium hydroxide: a critical review. I Endod J 1999;32:3619

21. Gomes BP, Souza SF, Ferraz CC, Teixeira FB, Zaia AA, Valdrighi L et al. Effectiveness of 2\% chlorhexidine gel and calcium hydroxide againstEnterococcus faecalis in bovine root dentine in vitro. Int Endod J2003;36:267-75

22. de Souza-Filho FJ, Soares A de J, Vianna ME, Zaia AA, Ferraz CC, Gomes BP. Antimicrobial effect and $\mathrm{pH}$ of chlorhexidine gel and calciumhydroxide alone and associated with other materials. Braz Dent J2008;19:28- 33
23. Gomes BP, Vianna ME, Sena NT, Zaia AA, Ferraz CC, de Souza Filho FJ.In vitro evaluation of the antimicrobial activity of calcium hydroxidecombined with chlorhexi $\neg$ dine gel used as intracanal medicament. OralSurg Oral Med Oral Pathol Oral Radiol Endod 2006; 102:544-50

24. Barbosa CAM, Goncalves RB, Siqueira JF, De Uzeda M. Evaluation of the antibacterial activities of calcium hydroxide, chlorhexidine, and camphorated paramonochlorophenol as intra canal medicament. A clinical and laboratory study. J Endod 1997;23:297-299

25. Signoretti FGC, Gomes BP, Montagner F, Tosello FB, Ja $\neg$ cinto RC. Influence of $2 \%$ chlorhexidine gel on calcium hydroxide ionic dissociation and its ability of reducing endotoxin. Oral Surg Oral Med Oral Pathol Oral Radiol Endod 2011;111:6538

26. Adl A, Shojaee NS, Motamedifar M. A comparison between the antimicrobial effects of triple antibiotic paste and calcium hydroxide against Entrococcus faecalis.Iran Endod J. 2012;7(3):149-55.

27. Mozayeni MA, Haeri A, Dianat O, Jafari AR. Antimicrobial effects of four intracanal medicaments on Enterococcus faecalis: An in vitro study. Iran Endod J. 2014;9(3):195-98.

28. Madhubala MM, Srinivasan N, Ahamed S. Antimicrobial effectiveness of intracanal medicaments on Enterococcus faecalis: Chlorhexidine versus octenidine. Int Endod J 2011;37(9):1287-9

29. Adl A, Shojaee NS, Motamedifar M. A comparison between the antimicrobial effects of triple antibiotic paste and calcium hydroxide against Entrococcus faecalis. Iran Endod J. 2012;7(3):149-55. 